Original Paper http://ajol.info/index.php/ijbcs http://indexmedicus.afro.who.int

\title{
Occurrence, distribution and composition of marine mammals in the bight of Bony, Nigeria
}

\author{
Gideon Wole OLAKUNLE* and Ajuonu NDUBISI
}

Nigerian institute for oceanography and marine research, no.3, Wilmot point, Victoria Island Lagos, Nigeria. ${ }^{*}$ Corresponding author; E-mail: gideolak@yahoo.com ; Mobile phone: +234- 8055-306-942.

\begin{tabular}{lll}
\hline Received: 03-01-2017 & Accepted: 06-07-2017 & Published: 28-02-2021 \\
\hline
\end{tabular}

\begin{abstract}
Information on the distribution, occurrence and population structure of cetaceans (whales and dolphins) of the Atlantic coast of Nigeria in West Africa remains fairly sparse to date, with few detailed studies being conducted on this valuable marine resource. This paper highlights the abundant cetacean community sighted in the Nigerian coastal waters and the respective importance of this area as a prime coastal habitat for these mammals. The secondary objective was the evaluation of this resource and development of appropriate management policies. Opportunistic data was collected on board six different marine vessels belonging to some international oil companies (IOC) in Nigeria, whose primary objective was to conduct seismic operations. 8,327 hours and 36 minutes of effort was logged during 2 wet and 3 dry seasons respectively, covering almost $880 \mathrm{~km}^{2}$ at a depth range of 10 to $70 \mathrm{~m}$. The total number of individuals recorded was 2199 of which $80 \%$ were dolphins and $20 \%$ were whales. Out of these, $55.14 \%$ was sighted at depth range of $21-30 \mathrm{~m}$. This was followed by $30.42 \%$ recorded at depth range of $31-40 \mathrm{~m}$. The least frequency of $0.75 \%$ was recorded at depth range of 61-70m. Five hundred and twenty-five (525) individual whales was recorded, out of which $77.14 \%$ were adults and $22.86 \%$ were juveniles, while 1674 individual dolphins were recorded with $52.63 \%$ juveniles and $47.37 \%$ adult. Four species of dolphins were identified. The bottlenose dolphins, Tursiops truncatus was the most abundant owing to the large size of the groups observed, followed by common dolphin, Delphinus delphis. All species of dolphins identified occurred throughout the sampling months. Two species of whales were identified with the humpback whale (Megaptera novaeangliae) predominant and killer whales (Orcinus orca) which seem to be present in just a part of a year. Nigerian coastal water is moderately rich in cetacean diversity, which is currently underreported due to limited research.
\end{abstract}

(C) 2021 International Formulae Group. All rights reserved.

Keywords: Whales, dolphins, species diversity, opportunistic surveys, Nigeria.

\section{INTRODUCTION}

Cetaceans are marine mammals that are primarily ocean-dwelling and migratory in nature. (Jefferson et al., 1993). They play a significant role in the balance of the marine ecosystem where they represent the top predators and the most important species within the marine ecosystem. Cetaceans are divided into two suborders: Mysticeti (baleen whales) and Odontoceti (toothed whales, 
which include dolphins and porpoises). The toothed whales use their teeth for catching fish, squid or other marine life that they then swallow whole (Rice,1998). Baleen whales do not have teeth, but have plates made of keratin that act as a giant filter, straining small animals from the seawater. Not all Mysticeti feed on plankton: the larger whales tend to eat small shoaling fish, such as herrings and sardine. One species of Mysticeti, the Gray Whale (Eschrichtius robustus), is a benthic feeder, primarily eating sea floor crustaceans (Rice 1998). These marine mammals spend their entire lives in the water and most of the times (>90\% for most species) entirely submerged below the surface, when at surface, cetaceans bodies are almost entirely below the water surface, with only me blowhole exposed to allow breathing. This makes cetaceans more difficult to locate visually,(Robinson et al., 2007).

Cetaceans have low reproductive rates with only one calf being born at a time and a long time between calving. The smaller cetaceans such as the porpoises can have a calf every year but in other larger species it may be as long as four years before the next calf is born. Cetaceans are the only mammal other than humans known to have a post-reproductive period when ovulation stops and this has only been observed in a few species. This low reproductive rate is offset by the fact that they are generally long lived and can therefore produce many calves in one lifetime. The average life span of a cetacean ranges from 20 to 40 years with some species being considered old when they are 15 compared to others which cam live for 80 years.

Defining geographical ranges and distribution limits for highly mobile marine species such as cetaceans is intrinsically difficult. Nevertheless, many studies have shown that the distribution of cetaceans (especially in relation to foraging areas) is linked to environmental features, both physiographic (e.g. water depth and oceanographic (such as temperature and chlorophyll-a (chl-a) concentrations) at various scales (Baumgartner et al., 2001; Murase et al., 2002; Tynan et al., 2005; Marubini et al., 2009; Scott et al., 2010). Such relationships may be either direct or indirect. Thus, temperature may have direct and indirect effects on cetacean distribution, for example through its effects on the energetic costs of thermoregulation (MacLeod et al., 2009) and on the distribution of fish, cephalopod and zooplankton prey (Murase et al., 2002; Tynan et al., 2005). As evident from recent interest in defining characteristics of Essential Fish Habitat (Valavanis, 2008), the distributers fish and cephalopods have been found to be related to numerous oceanographic and environmental features, including depth (Gil de Sola, 1993), upwelling (Guerra, 1992; Rubi'n, 1997) and fronts, which create hotspots of primary and secondary production (Rubi'n, 1994). The horizontal and vertical mobility of the prey of cetaceans, combined with temporal variability, make it difficult to predict habitat use of cetaceans over small spatial and temporal scales. In general, it is easier to measure environmental parameters accurately than fine-scale prey distribution. According to Torres et al. (2008), environmental parameters generate better models of cetacean habitat preferences due to the relative ease of accurately measuring them at an appropriate scale. Understanding the relationships between cetacean distributer and environmental factors is necessary to identify cetacean habitat requirements, to predict their distribution and provide insights into their feeding habits. In turn, this provides valuable information to underpin conservation measures directed at cetaceans, for example identifying areas suitable for designation as Special areas of Conservation. In addition, implementation of Ecosystem Approach to Fisheries Management (EAFM) requires collection of data on the status of all ecosystem components, including top predators. There had been paucity of 
information about marine mammal species inhabiting the coastal waters of Nigeria, and until recently most information was based on historical catches of large whales in the gulf of Guinea (Gideon and Williams, 2014).Nigeria like most oil producing countries in the region has received increasing focus from offshore industry, and some companies have engaged Marine Mammal Observers (MMOs) during geophysical seismic surveys along Nigerian coast. While marine mammals observers are primarily onboard to mitigate against any potentially adverse impacts on marine fauna, the use of trained indigenous marine biologists has also provided an invaluable opportunity to collect scientific data which was almost nonexistent (Olakunle and Myade, 2014). Dedicated scientific surveys had been moderately carried out in countries like Côte d'Ivoire, Ghana, Togo and Benin, Gabon \&. Cameroun with the exclusion of Nigeria, leaving the nation with little or no scientific information that can enhance policies formulation. This has created a knowledge or information gap which this study tends to bridge. This publication is to document the different species of marine mammals sighted within the Nigerian coastal waters for the purpose of monitoring the population dynamics so as to scientifically determine possible threats to this invaluable marine resource.

\section{MATERIALS AND METHODS}

\section{Study Area}

The survey covers about $800 \mathrm{~km}^{2}$ located in the bight of Bonny $\left(3^{\circ} 50^{\prime} \mathrm{N} \&\right.$ $70^{\circ} 10^{\prime} \mathrm{E}$ to $4^{\circ} 50^{\prime} \mathrm{N} \& 80^{\circ} 40^{\prime} \mathrm{E}$ ) in the oil rich south-south region of the Niger delta area of Nigeria. The site is delineated OML (oil mining license). It consists of OML 67, 68, 69and 70 (Figure 3).

\section{Survey}

\section{Technique}

Opportunistic data was collected on board six different marine vessels whose primary objective was to collect seismic data. The overall observation effort was 8,327 hours 36minutes accomplished over a period of 26months (Nov.2007-Dec.2009) covering $800 \mathrm{~km}^{2}$. The presences of cetaceans were sought for before a survey line was started, and the start was delayed by at least 20 minutes if cetaceans are within 500 metres (mitigation zone). Two experienced cetacean observers worked as onboard observers throughout the survey from the highest vantage points aboard (14.5m a.w.1.), following standardised protocols and data collection methods. Data were collected throughout daylight hours. During marine mammal "search mode," the observers scanned $360^{\circ}$ around the vessel with the naked eye and with binoculars. Scans focused on the area within $1 \mathrm{~km}$ of the air gun array (situated 180 or $340 \mathrm{~m}$ astern of the vessel) and on the $180^{\circ}$ sector ahead of the ship in order to detect animals before they entered the $500 \mathrm{~m}$ exclusion zone around the air gun array.

Photographs were taken at the maximum of individuals possible and dorsal fins for individual recognition and confirmation of group size and group composition, with digital cameras equipped with 75-300 mm zoom lenses. Surveys were only undertaken in sea states of Beaufort wind scale of 4 or more nautical miles in visibility to ensure that few or no cetaceans present at the surface were missed. However, any cetaceans not at the surface were likely to be missed. While this bias will have relatively little impact on observations of surfacedwelling cetaceans, it is likely to lead to an under-recording of deep and long diving species, hence a correction factor of 1.5 for sighting per unit effort (SPUE) was used. (adapted from Kawamuro et al.,1977; Anglis et al., 2007).

Species were identified through Photoidentification method which is the utilisation of computer-assisted matching software for the identification of known species (Morten, 
2000). The species, school size and composition were recorded for each encounter. School sizes were defined as small $(<30)$, medium (31-60) and large (> 60). In order to have a value of occurrence of cetaceans relative to the sampling effort (hours) a number of sightings per unit of effort (SPUE), expressed as the number of sightings per hour of search effort at sea was calculated. Time (hours) was used as the unit of effort rather than distance. Marine mammal monitoring took place between $06.00 \mathrm{hr}$ to 18.00 GMT.

\section{Statistical analysis}

Information from JNCC record of Sighting forms were analyzed using descriptive statistics, correlation and Analysis of variance (ANOVA) at $\mathrm{p}=0.05$.

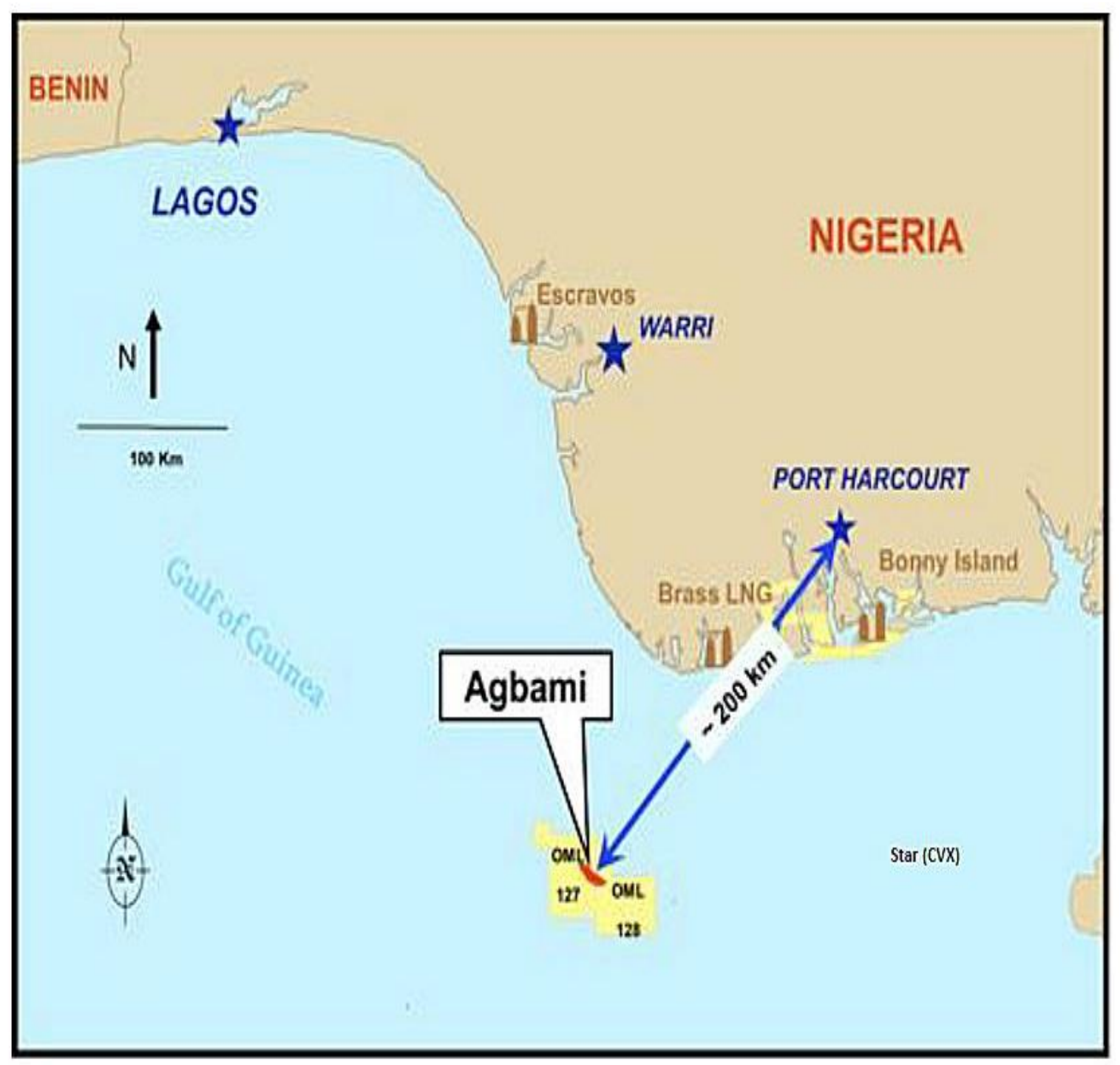

Figure 3: Map of study site. 


\section{RESULTS}

Population structure and Sightings per unit effort (SPUE) in relation to various water depth ranges (10 $\mathrm{m}$ interval) was presented in Tables 1 and 2 for whales and dolphins respectively. Records of sighting showed that animal groups consist of adults and calves (juveniles) both for the whales and dolphins. Two hundred and seventy-seven (277) sightings comprising of 189 (68\%) sightings of whales and 94 (32\%) sightings for dolphins was recorded, whales recorded more adults than juveniles while the adult dolphins were less in number than the juveniles (Figure 2). Sighting per unit effort (SPUE) value of 0.06 ind./hr was estimated for whales and 0.20 ind./hr (see Tables $1 \& 2$ ).

\section{Whales}

Two species of whales were identified with the humpback whale (Megaptera novaeangliae) as the dominant specie, killer whales (Orcinus orca) which was sighted once seem to be present in just a part of a year. Total number of individual whales (adults and calves) sighted within the period is

525 comprising of 405 adults $(77.14 \%)$ and

120 juveniles (22.86\%). Four hundred and eighty-five whales $(92.38 \%)$ were sighted between 10 and 40 meters. The highest number of $219(41.71 \%)$ of individuals sighted was recorded at the depth range of $21-30 \mathrm{~m}$, this is closely followed by depth range of 31 $40 \mathrm{~m}$ with a total of $184(35.05 \%)$ of individuals sighted. The least number was recorded at the depth range of $51-60 \mathrm{~m}$ with only one $(0.19 \%)$ individual (Table 1$)$.
Whales were found to be more abundant between the months of June to November. This pattern was consistent, though the number of individual sightings dwindled the following year (Figure 2).

\section{Dolphins}

Four species of dolphins were identified. The pantropical spotted dolphin (Stenella attenuata), bottlenose dolphin (Tursiops trucantus), Common dolphin (Delphinus delphis) and hump-backed dolphin (Sousa teuszii) . The bottlenose dolphins Tursiops truncatus, being the most abundant owing to the large size of the groups observed, followed by Stenella attenuata, the least abundant was Sousa teuszii. All these species were sighted all year round with oscillations in peak period which follows no definite pattern throughout the sampling period (Figure 2). Total number of individual dolphins (adults and calves) sighted within the period is 1674 comprising of 793 adults (47.37\%) and 881 juveniles (52.63\%). One thousand and eight individuals $(60.21 \%)$ were sighted at the water depth of 21 and 30meters followed by $443(26.46 \%)$ of individuals sighted at the depth range of $31-40 \mathrm{~m}$. The least number was recorded at the depth range of $61-70 \mathrm{~m}$ with only $8(0.48 \%)$ individuals. Calves were observed to stay close to their mothers and occasionally "bow ride" beside her in order to keep up with the adults. However they do not join their mothers when they dive deeply to feed and remain with the others in the group at this time. 
Table 1: SPUE of Whales in Relation to Depth.

\begin{tabular}{ccccc}
\hline Depth range & Adult & Calves & Total & SPUE \\
\hline $10-20$ & 44 & 38 & 82 & 0.01 \\
$21-30$ & 155 & 29 & 184 & 0.02 \\
$31-40$ & 183 & 36 & 219 & 0.03 \\
$41-50$ & 12 & 11 & 23 & 0.003 \\
$51-60$ & 1 & 0 & 1 & 0.0001 \\
$61-70$ & 11 & 6 & 17 & 0.002 \\
Total & 405 & 120 & 525 & 0.06 \\
\hline
\end{tabular}

Table 2: SPUE of Dolphins in Relation to Depth.

\begin{tabular}{ccccc}
\hline Depth range & Adult & Calves & Total & SPUE \\
\hline $10-20$ & 60 & 66 & 126 & 0.02 \\
$21-30$ & 501 & 507 & 1,008 & 0.12 \\
$31-40$ & 162 & 281 & 443 & 0.05 \\
$41-50$ & 36 & 15 & 51 & 0.006 \\
$51-60$ & 29 & 9 & 38 & 0.005 \\
$61-70$ & 5 & 3 & 8 & 0.001 \\
Total & 793 & 881 & 1,674 & 0.20 \\
\hline
\end{tabular}

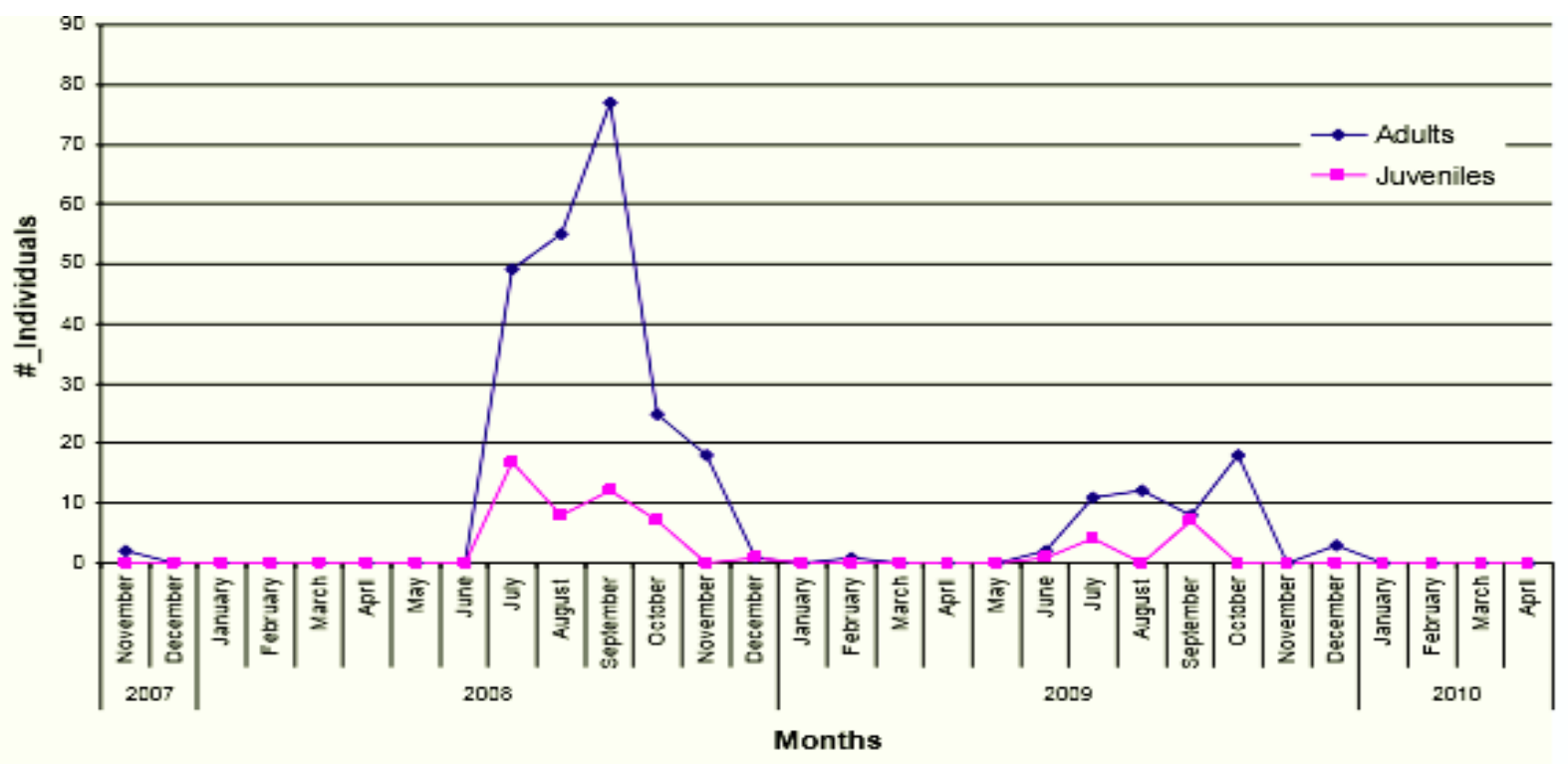

Figure 1: Total number of adult and juvenile whales recorded. 


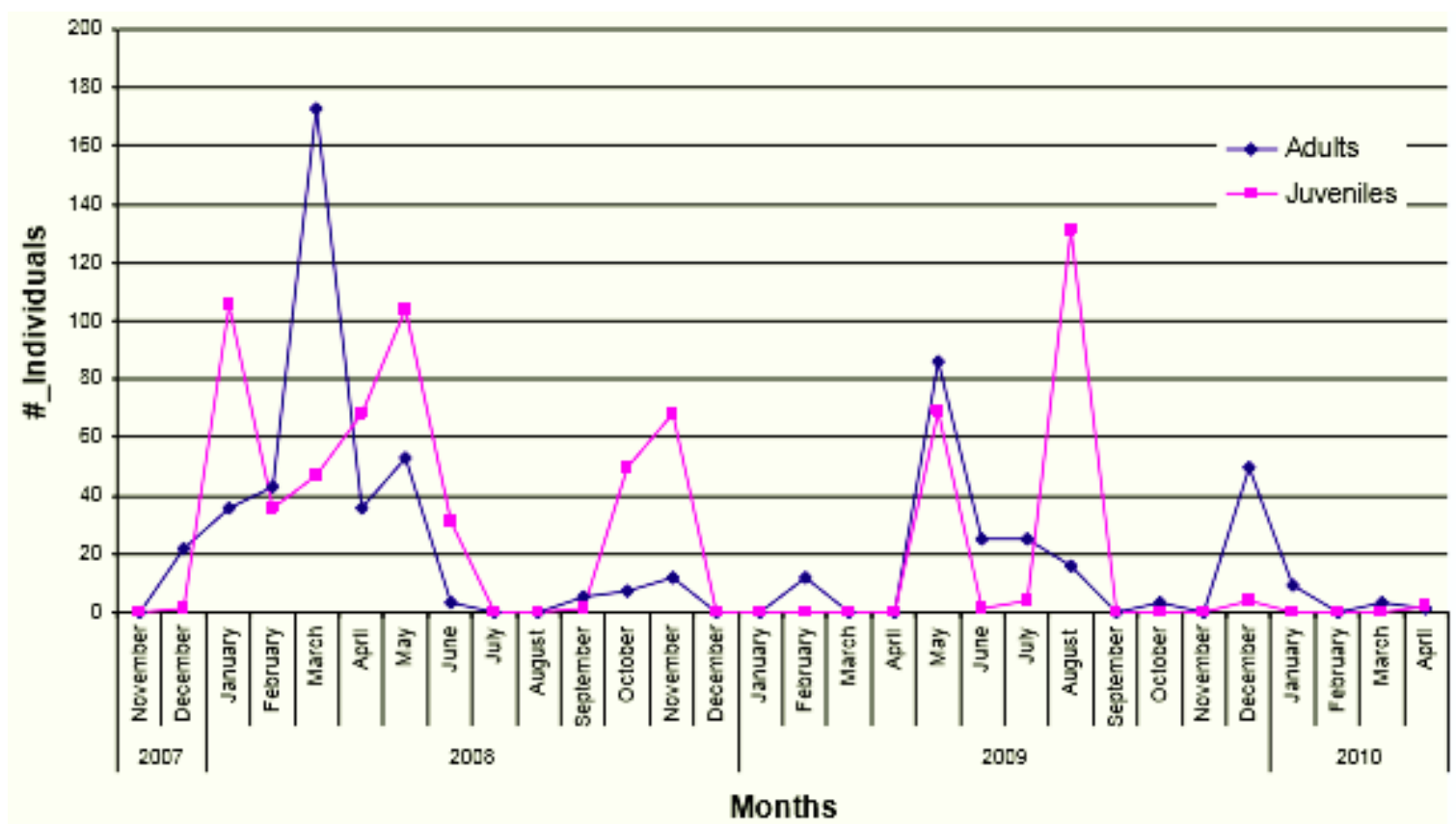

Figure 2: Total number of adult and juvenile dolphins recorded.

\section{DISCUSSION}

Free-ranging whales and dolphins, which are visible above water for only short periods, are notoriously challenging research subjects. The lack of precision in most cetacean research is best exemplified by population estimates, which can vary over orders of magnitude for the same cetacean population, i.e. we cannot even accurately count most populations of cetaceans with any degree of confidence. Nevertheless, data obtained as these are potentially informative and could help curb the growing threat to marine mammals in our oceans and provide some respite for some endangered cetaceans species.

Humpback whales (Megaptera novaeangliae) feed in Antarctic waters during the austral summer and migrate to their breeding grounds in subtropical and tropical waters during the winter; this explains the reason for their abundance between the months June and November of the year. Historical whaling records also suggest that the bight of Bonny, Nigeria, located in the Gulf of Guinea, serves as a possible breeding ground for this animal. Of the 189 groups encountered, mother/calf pairs made up a large proportion (68\%). Given the high percentage of mother/calf pairs, sometimes with very young calves, and the low frequency of mating activity, the waters of Nigeria may be primarily serving as a calving and nursing or resting area for Megaptera novaeangliae. Opportunistic sightings events (mentioned by fishermen) suggested presentday abundance of humpback whales in Nigerian coastal waters. Two stranding of this specie have also been recorded between 1999 and 2006 in the Lagos bar beach (pers. comm. A. Williams, 2009). This confirms the assertion that this species frequents Nigerian coastal waters.

Humpback whales in Nigerian waters 
are actively migrating. Any disturbance could affect these animals. Whales require personal space, and harassment may severely stress them-possibly causing accidents both for humans and whales if the whales feel threatened. This is especially important in the case of the adults with claves, which may be either resting or sucking. (Department of Environment and Heritage ,2012). Whales were more likely to avoid a boat moving within 100 metres (Stamation et al., 2010). Similar studies conducted by researchers in New Caledonia showed that whales significantly increased their drive time and changed their direction when boats were within 1000 metres (Schaffer et al., 2009; Scheidat et al., 2004). It implies that when cetaceans are disturbed they move away, resulting in decreased abundance, this possibly explained for the decrease in the sighting rate of whales in the second year of the survey.

The four species of dolphins identified; the pantropical spotted dolphin (Stenella attenuata), bottlenose dolphin (Tursiops trucantus), Common dolphin (Delphinus delphis) and hump-backed dolphin (Sousa teuszii) are seen year round and may be considered permanent members of the cetacean community found in Nigeria coastal waters.

The spatial distribution of cetaceans is influenced by the distribution of fish, cephalopod and zooplankton prey (Murase et al., 2002; Tynan et al., 2005). This is evident from the catch composition of the fisher folks around the survey area. Common dolphins feed on small schooling fish as well as squid and crustaceans, and prey preference varies with habitat and location (Pusineri et al. 2007; Perrin 2002). Cetaceans identified appear to take advantage of these several prey species found around the surveyed area where artisanal fishery is intensely active, though there was no study of stomach content. The result shows that Nigerian waters shelter an abundant and diverse population of cetaceans. These preliminary results also corroborate a trend of cetaceans' occurrence and distribution previously obtained by author offLagos coast. (Gideon and Williams, 2014). The result obtained might not completely capture all the species as with all cetacean surveys, positive identification proved difficult at times. However, with continuous trainings identification skill could be improved. Further data collection in the future surveys may add to the present knowledge on cetaceans' population frequenting Nigerian coastal waters. This will enable the relevant authorities to take appropriate policy decisions. Therefore, additional surveys are required to provide an accurate knowledge of each species status promoting long term monitoring for the conservation of the cetacean population.

\section{Conclusion}

The six cetacean species recorded during this survey may not be a complete representation of all the species present in Nigerian coastal waters. Nevertheless, the results confirm a similar trend of occurrence and distribution previously documented along the gulf of Guinea. The result shows that Nigerian waters shelter an abundant and diverse population of marine mammals. Therefore, dedicated surveys are required from time to time to provide an accurate data of the species diversity and status for long term monitoring and consequently for conservation and tourism benefits. 


\section{ACKNOWLEDGEMENTS}

This work was facilitated by Exxonmobil Nigeria Limited, whose support is gratefully acknowledged. Thanks are due Allolis geosciences, the sub-contractor that provided this platform of opportunity. The cooperation of the oil and gas industries, seismic exploration companies and the crews of seismic survey vessels is gratefully acknowledged. Numerous observers recorded the data, including ships' crews - their vigilance in keeping watch for marine mammals is appreciated. Albert Gadzekpo, Marsel Umunakwe, Anjuonu Ndubisi, Akanbi Williams, Edward Ajado, Emmanuel Friday, Femi Fakayode and Micheal Oyebamji, all from marine biology, section of Nigerian Institute for Oceanography and Marine research Lagos, Nigeria.

\section{REFERENCES}

Angliss RP, Outlaw RB. 2007. Alaska Marine Mammal Stock Assessments, 2006. NOAA Technical Memorandum NMFSAFSC-168. 244p.

Baumgartner MF, Mullin KD, May LN, Leming TD. 2001.Cetacean habitats in the northern Gulf of Mexico. Fishery Bulletin, 99: 219 -239.

Department of Environment and Heritage. 2012. Approaching whales and dolphins in NSW, Sydney, Government of New South Whales [at://www.environ.nsw.gov.au/animals/ Whale s.htm]

Gilde Sola L. 1993. Las pesqueri' as demersalesdel Mar de Albora'n (Surmediterra'neoibe'rico). Evolucio'n en los u'ltimosdecenios. Informes Tecnicos Instituto Espan'ol de Oceanografi'a.Guerra, A. 1992. Mollusca, Cephalopoda. Fauna Ibe'rica,
Vol. Museo Nacional de Ciencias Naturales, Madrid.

Jefferson TA, Leatherwood S, Webber MA. 1993. Marine mammals of the world. FAOlspecies identification. FAO, Rome, 320 pages.

Macleod CD, Weir CR, Santos MB, Dunn TE. 2009. Temperature-based summer habitat partitioning between whitebeaked and common dolphins around the United Kingdom and Republic of Ireland. Journal of the Marine Biological Association of the United Kingdom, 88: 1193 - 1198.

Murase M, Matsuoka K, Ichii T, Nishiwaki S. 2002. Relationship between the distribution of euphausiids and baleen whales in the Antarctic (35_E145_W). Polar Biology, 25(2): 135-145.

Olakunle GW, Akanbi WB. 2014. Occurrence and species diversity of delphinids offLagos shore, Nigeria. Int. J. Biol. Chem. Sci., 8(6): 2578-2587.

Olakunle GW, Myade EF. 2014. Effect of seismic operations on cetaceans sightings off-shore Akwa Ibom State, south-south, Nigeria. Int. J. Biol. Chem. Sci., 8(4): 1570-1580.

Perrin WF. 2002b. Common Dolphins. In Encylopedia of Marine Mammals, Perrin WF, Wursig B, The wissen JGM (eds). Academic Press: San Diego. 245 -248.

Pusineri C, Meynier V, Spitz J, Hassani S, Ridoux V. 2007. Food and Feeding Ecology of the Common Dolphin (Delphinus delphis) in the Oceanic Northeast Atlantic and Comparison with its Diet in Neritic Areas. Marine Mammal Science, 23(1): 30 -34.

Schaffer A, Madon B, Garrique C, Constantine R. 2009. Avoidance of whale watching boats by humpback 
whales in their main breeding ground in

New Caledonia, scientific Committee, International Whaling Commission.

Scheidat M, Castro C, Gonzalez J, Williams R. 2004. Behavioural responses of humpback whales (Megaptera novaeangliae) to whale-watching boats near Isla de la Plata, Machalilla National Park, Ecuador. Journal of Cetacean Research and Management, 6 (1): 63-68. Stamation KA, Croft DB, Shaughnessy PD, Waples KA, Briggs SV. 2010. Behavioural responses of humpback whales (Megaptera novaeangliae) to whale-watching boats on the southeastern coats of Australia. Marine Mammals Science, 26 (1): 98-122.
Torres LG, Read AJ, Halpen P. 2008. Finescale habitat modeling of a top marine predator: do prey data improve predictive capacity? Ecological Applications, 18: 1702-1717.

Tynan CT, Ainley DG, Barth JA, Cowles TJ, Pierce SD, Spear LB. 2005. Cetacean distributions relative to ocean processes in the northern California Current system. Deep-sea Research II, 52: 145167.

Valavanis VD, Pierce GJ, Zuur AF, Paliaexis A, Saveliev A, Katara I, Wang J, 2008. Modeling of essential fish habitat based on sensing, spatial analysis and GIS. Hydrobiologia, 612: 5-20. 